\title{
A New Method of the Load Compensation Use During Creation of Post Blackout Start-up Path in Power System
}

\author{
Robert Malkowski ${ }^{1}$, Maciej Losinski ${ }^{2}$, Stanislaw Czapp ${ }^{1}$, Robert Kowalak ${ }^{1}$ \\ ${ }^{I}$ Faculty of Electrical and Control Engineering, Gdansk University of Technology, \\ Narutowicza 11/12 St. 80-233, Gdansk, Poland \\ ${ }^{2}$ Control Engineering and Relay Protection Department, Zarnowiec Pumped-Storage Power Plant, \\ 84-250, Czymanowo, Poland \\ m.losinski@ewz.pl
}

\begin{abstract}
Process of power system restoration, especially after blackout, is very complicated logistically and technically. In order to restore thermal power plant in power system, as a source of power hydro power plant is commonly used. The distance between these power plants may be relatively high even over $500 \mathrm{~km}$. High voltage overhead transmission lines to connect the power plants during the creation of post blackout start-up path are switched on under no load condition. Relatively high value of natural reactive power of these lines makes that value of voltage at the end of the switched line may reach an unacceptable high level, in spite of application of typical algorithm of automatic voltage regulator of synchronous generator.

In the paper a new method of effective use of load compensation during creation of post blackout start-up path is proposed. Theoretical assumptions and simulation results of an investigation are presented. An experiment performed in the Polish Power System is also described. This experiment proved that the method proposed by the authors is advisable. The method may be utilized by power system operators for power system restoration process in emergency conditions.
\end{abstract}

Index Terms-Load compensation; power system analysis computing; power system experiment; power system restoration; voltage control.

\section{INTRODUCTION}

Start-up path is created between the power source which is mostly hydro power plant and thermal power plant enables it to start. Due to level of transferred power and long distances, in Polish Power System such path is formed by using the high voltage (HV) $110 \mathrm{kV}$ or the extra high voltage (EHV) $220 \mathrm{kV}$ and $400 \mathrm{kV}$ transmission lines. In case of large distances between a source power plant and a thermal power plant using the HV $110 \mathrm{kV}$ lines for start-up path creation has some limitations. The principal disadvantage is the large number of substations in the circuit of the created start-up path. The fact that not all substations are remotely controlled generates a big logistical challenge (communication, protection devices settings, etc.). In turn, for large length of the EHV transmission lines charging

Manuscript received 8 November, 2015; accepted 15 February, 2016. reactive power can reach high values (Fig. 1).

Creation of starting path for the restoration of power system after blackout is a complex and difficult operation. This operation - as an experiment - has been carried out at Polish Power System many times. The analysis of publications which describes such experiments [1]-[14] gives a conclusion that much attention is paid to the issues of protection relay settings, coordination and communication of power system dispatchers and turbine governor operation algorithms. Unfortunately, there is not much information about the operation of automatic voltage regulator (AVR) of synchronous generator during post black-out creation of start-up path [8], [9].

In the earlier article [15], the authors presented the results of theoretical and simulation studies of two important issues, connected with automatic voltage regulator (AVR), omitted in the publications describing the mentioned power system experiments. The first of them is the operation of underexcitation limiter (UEL), the second ones are proper settings of load compensation (LC) impedance.

The main aim of this paper it to present the result of the experiment - creation of post blackout path in the Polish Power System. This experiment was carried out according to a new method of effective use of load compensation (LC), proposed by the authors.

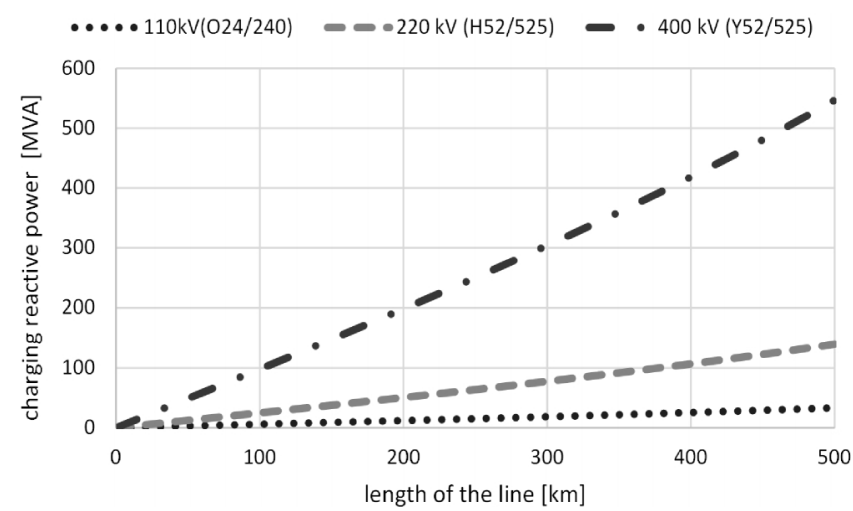

Fig. 1. Charging reactive power as a function of length of transmission line. Symbols in parentheses present the type of line / cross-section in $\mathrm{mm}^{2}$ [15]. 


\section{LOAD COMPENSATION OPERATION}

\section{A. Theory}

Load compensation carried by the automatic voltage regulator has been used for many years in the Polish Power System [8], [9], [15]. Compensation, using generator current phasor measurement and a certain adopted impedance, allows replacing the voltage measured at the generator terminals with a synthesized voltage in a selected fictional point, shifted toward the generator's equivalent electromotive force, or towards the grid as follows

$$
V_{\mathrm{C}}=\left|\underline{V}_{\mathrm{T}}+\underline{Z}_{\mathrm{LC}} \times \underline{I}_{\mathrm{T}}\right|,
$$

where $V_{\mathrm{C}}-$ voltage setpoint, $\underline{V}_{\mathrm{T}}-$ voltage setpoint by noload running, $\underline{Z}_{\mathrm{LC}}-$ load compensation impedance, $\underline{I}_{\mathrm{T}}-$ generator current phasor.

The compensation is usually determined with respect to the base generator impedance or the unit transformer reactance. The compensation of $50 \%$ of the unit transformer reactance $\left(X_{\mathrm{LC}}=0.5 X_{\mathrm{T}}\right)$ is illustrated in Fig. 2. In IEEE standard [16] the compensation is defined by the element shown in Fig. 3.

In Polish power plants during a normal operation the value of load compensation is equal to zero. Thus, only a voltage drop at internal impedance of synchronous generator is compensated. Droop characteristics of the generation unit is determined by the unit transformer impedance and the operation of coordinated reactive powervoltage controller (CRPC). During the creation of start-up path the CRPC is disabled. It should be emphasized that the CRPC operates much slower compared to the control executed directly by the AVR.

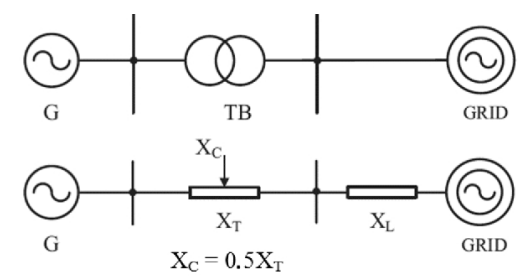

Fig. 2. Unit transformer reactance compensation [15].

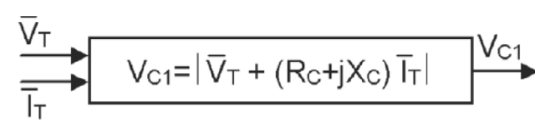

Fig. 3. Compensation element according to IEEE standard [16].

A proper setting of load compensation can contribute to the improvement of the voltage condition in the process of creating of start-up path. Switching on consecutive sections of the EHV transmission line will cause an increase value of reactive power generated by line capacity to earth (Fig. 1) and an increase of the load of generator. This according to the relation (1), will automatically reduce the AVR reference voltage.

\section{B. Simulation}

The simulation reflects the creation the start-path by applying the voltage from pumped-storage power plant to thermal power plant by EHV lines. The start-up path consisted of two transformers, approx. $80 \mathrm{~km}$ section of the
$400 \mathrm{kV}$ line and approx. $400 \mathrm{~km}$ section of the $220 \mathrm{kV}$ transmission line. Figure 4 shows a simplified diagram of created start-up path.

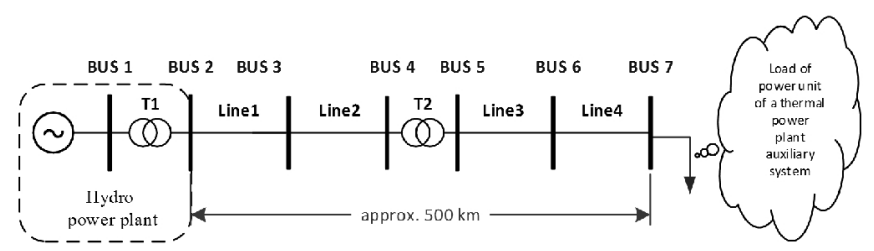

Fig. 4. Simplified diagram of the modelled start-up path [15].

The increase of generated reactive power by transmission lines causes an increase of the voltage. Currently, when a start-up path is created, the voltage is adjusted manually by changing the AVR reference voltage and/or transformer voltage ratio. Figure 5 presents the structure of the voltage regulator (AVR) prepared on the base of the standard [16].

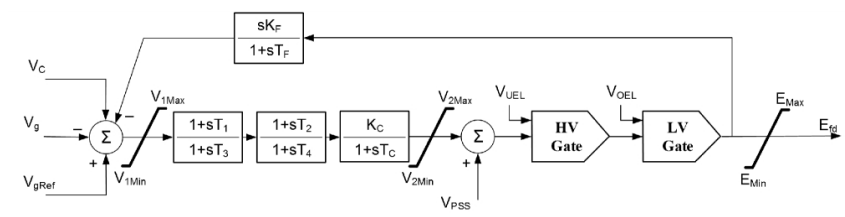

Fig. 5. Structure of the voltage regulator that was used in the simulations and experiment. $V_{\mathrm{IMax}}, V_{\mathrm{IMin}}, V_{\mathrm{AMax}}, V_{\mathrm{AMin}}, E_{\mathrm{Max}}, E_{\mathrm{Min}}-$ the limit values, $E_{\mathrm{Fd}}-$ excitation voltage, $V_{\mathrm{PSS}}$ - signal from Power System Stabilizer.

In order to investigate the impact of the settings of load compensation (LC), the following two options were examined:

- (LC+): load compensation enabled,

- (LC-): load compensation disabled.

In the described simulation the load compensation is disabled when the value of the load compensation impedance is $Z_{\mathrm{LC}}=0$. The load compensation is enabled when the value of the load compensation impedance is $Z_{\mathrm{LC}}>0$. The authors assumed that the value of the load compensation impedance should be equal to the unit transformer impedance $\left(Z_{\mathrm{LC}}=Z_{\mathrm{T}}\right)$. In such a case the voltage drop at the unit transformer is compensated.

The simulations assumed that the voltage regulation is done only by the automatic voltage regulator (AVR) of synchronous generator. The value of generator reference voltage and transformers voltage ratio (unit generatortransformer and grid transformer) was adjusted in such a way that in the most preferred case the voltage at the end of path does not exceed $1.1 V_{\mathrm{n}}$, where $V_{\mathrm{n}}$ is the nominal voltage of the grid. Figure 6 presents voltage variation at the following busses:

- BUS1 - busses of the synchronous generator,

- BUS2 - busses of the unit transformer,

- BUS7 - busses at the end of start-path.

When the load compensation is enabled $\left(Z_{\mathrm{LC}}>0\right.$, in the analysed case $Z_{\mathrm{LC}}=Z_{\mathrm{T}}$ ), one can see the voltage level has been significantly reduced (positive effect), compared to $Z_{\mathrm{LC}}=0$.

The creation of the start-path is usually carried out with the participation of only one power supply unit (synchronous generator). It may happen that there will need to use more than one power supply unit working on common buses. Then we should remember the need to meet the conditions for 
a parallel cooperation of generators.

One of them is a requirement to ensure the stable parallel cooperation. Accordingly, the value of load compensation should be set so that the reactance (impedance) of each power supply unit relative to the node of parallel cooperation is higher than zero.
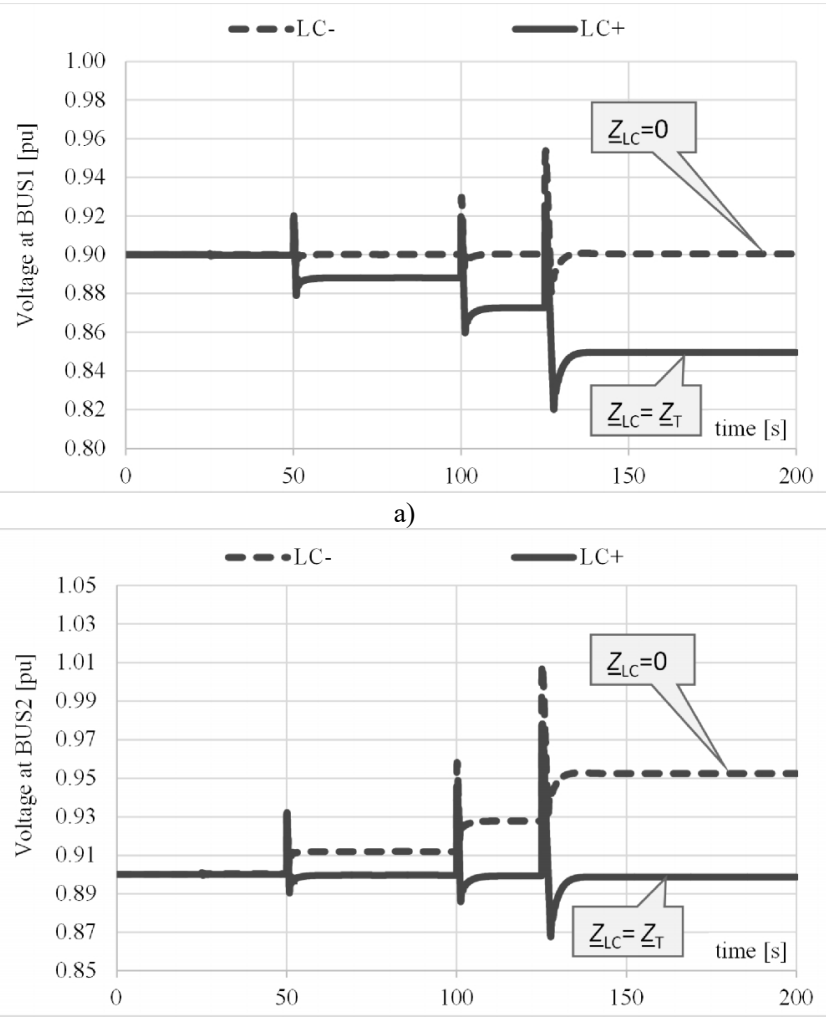

b)

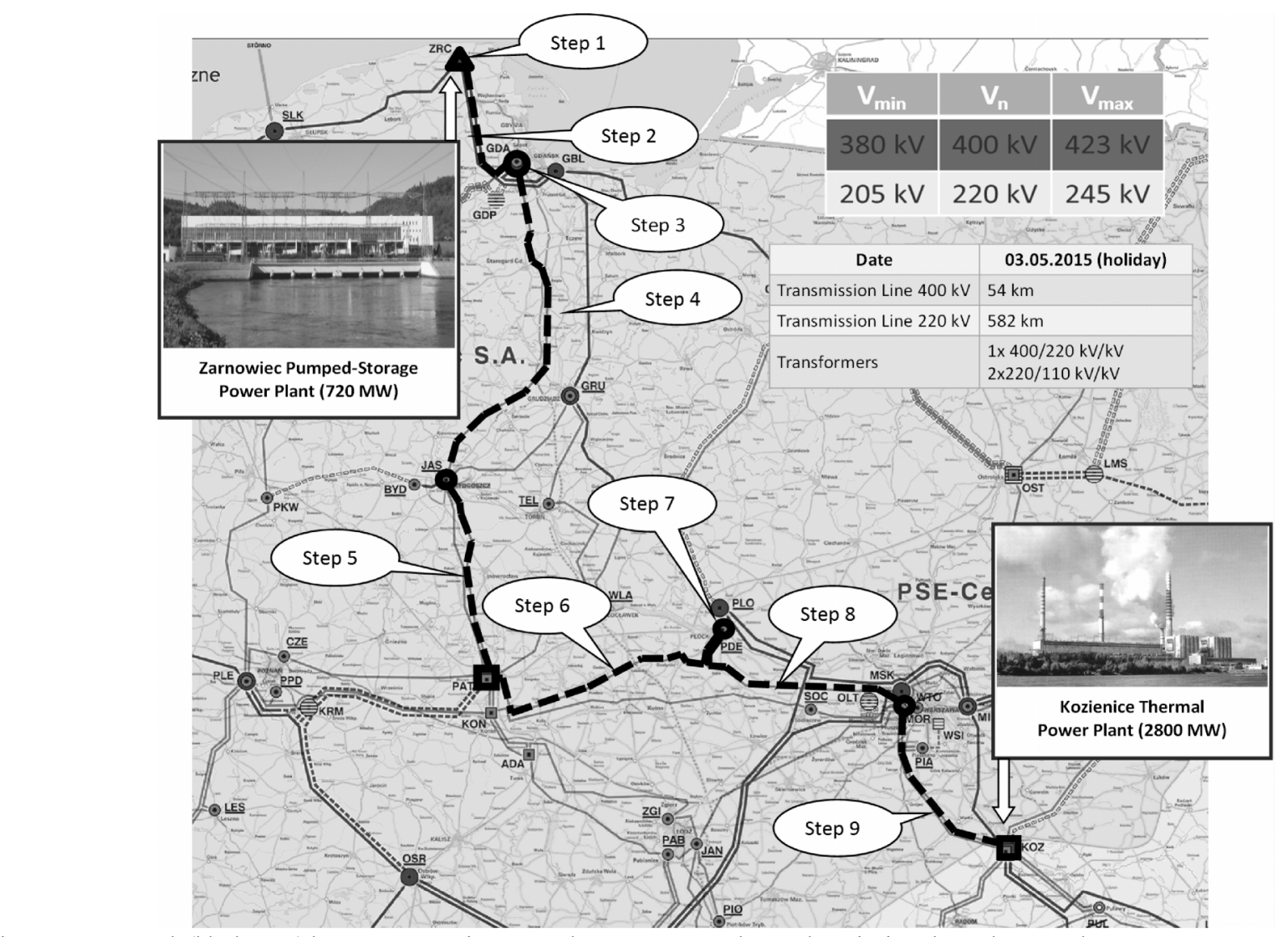

Fig. 7. Start-up path (black trace) between Zarnowiec Pumped-Storage Power Plant and Kozienice Thermal Power Plant.

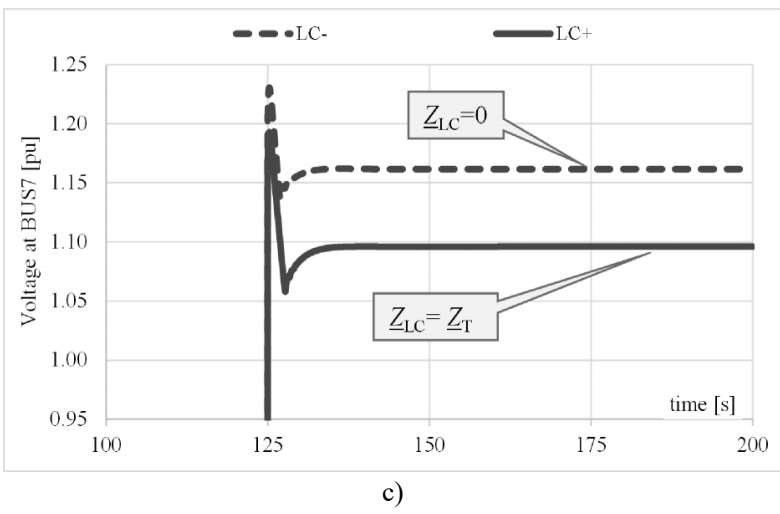

Fig. 6. Voltage variation when the load compensation is enabled (LC+) or disabled (LC-), at: a) BUS1, b) BUS2, c) BUS7.

\section{AN EXPERIMENT IN THE POWER SYSTEM}

In Polish Power System an experiment was performed in May of 2015 by bringing into start-up of power unit at Kozienice Thermal Power Plant (TPP) from Zarnowiec Pumped-Storage Power Plant (PSP) through a dedicated transmission line path. Start-up path was created with $400 \mathrm{kV}$ and $220 \mathrm{kV}$ lines with a total length of $636 \mathrm{~km}$ (Fig. 7).

Zarnowiec Pumped-Storage Power Plant is located in the northern part of Poland and it is equipped with four reversible hydro-units with total power of $720 \mathrm{MW}$.

Kozienice Thermal Power Plant is the largest coal-fired power plant in Poland, which consists of 10 blocks with a total power of $2800 \mathrm{MW}(8 \times 225 \mathrm{MW}+2 \times 500 \mathrm{MW})$. For experiment purposes unit no. 2 (180 MW) at Zarnowiec PSP, and units no. 7, $8(2 \times 220 \mathrm{MW})$ at Kozienice TPP were chosen. 
The purpose of the planned power system experiment was to test the possibility of:

- supplying the voltage and start-up power from Zarnowiec PSP to Kozienice TPP through dedicated $400 \mathrm{kV}$ and $220 \mathrm{kV}$ transmission lines,

- start some auxiliary devices at 220 MW Kozienice TPP unit,

- using transformers $220 / 110 \mathrm{kV} / \mathrm{kV}$ working in parallel to compensate the reactive power of transmission lines.

During the experiment automatic voltage regulator (AVR) of hydrogenerator at Zarnowiec PSP worked with activated load compensation - this solution is proposed by the authors. Parameters of the load compensation (LC) were chosen in such a way as to compensate $100 \%$ of the voltage drop at the unit transformer $240 \mathrm{MVA} 15.75 / 400 \mathrm{kV} / \mathrm{kV}\left(Z_{\mathrm{LC}}=Z_{\mathrm{T}}\right)$. With so set of the load compensation, voltage level at $400 \mathrm{kV}$ Zarnowiec substation should remain at a constant level.

Table I presents consecutive steps of creation of the startup path, and Fig. 8 shows the voltage (V_400_HZ2) and reactive power (Q_400_HZ2) variation at Zarnowiec substation during creation of start-up path to Kozienice TPP. Switching the following line sections causes a transient in the load of generator, voltage at Zarnowiec bus remains at constant value of $380 \mathrm{kV}$. It is a confirmation of the correct operation of load compensation function.

TABLE I. THE STEPS TO CREATE OF THE START-UP PATH.

\begin{tabular}{|c|c|}
\hline Step & Description of activities \\
\hline 1 & applying voltage to the $400 \mathrm{kV}$ Zarnowiec substation \\
\hline 2 & Zarnowiec - Gdansk $400 \mathrm{kV}$ line inclusion $(54 \mathrm{~km})$ \\
\hline 3 & $\begin{array}{c}400 / 220 \mathrm{kV} / \mathrm{kV} \text { autotransformer inclusion in Gdansk } \\
\text { substation }\end{array}$ \\
\hline 4 & Gdansk - Jasiniec $220 \mathrm{kV}$ line inclusion $(158 \mathrm{~km})$ \\
\hline 5 & Jasiniec - Patnow $220 \mathrm{kV}$ line inclusion $(101 \mathrm{~km})$ \\
\hline 6 & Patnów - Podolszyce $220 \mathrm{kV}$ line inclusion $(123 \mathrm{~km})$ \\
\hline 7 & $\begin{array}{c}\text { reactive power load inclusion (change the two parallel } \\
220 / 110 \mathrm{kV} / \mathrm{kV} \text { autotransformers ratio in Podolszyce } \\
\text { substation }), Q_{\text {load }}=25 \text { Mvar }\end{array}$ \\
\hline 8 & $\begin{array}{c}\text { Podolszyce }- \text { Mory } 220 \mathrm{kV} \text { transmission line inclusion } \\
(108 \mathrm{~km})\end{array}$ \\
\hline 9 & Mory - Kozienice $220 \mathrm{kV}$ line inclusion $(92 \mathrm{~km})$ \\
\hline
\end{tabular}

Figure 8 also shows the voltage and reactive power variation (V_400_HZ2* and Q_400_HZ2* respectively) in a situation when the load compensation function would be disabled. In this case the voltage regulator at all times maintains a constant voltage at generator bus. As a result, an increase of the load of the generator (reactive power) causes a voltage increase at ZRC bus.

Table II shows the voltage levels at all nodes registered in successive stages during creation start-up path. Fig. 9 shows the voltage values along the established start-up path between Zarnowiec PSP and Kozienice TPP. The dashed line shows the voltage along the path when load compensation in Zarnowiec PSP is disabled (classic assumption). These values were determined using a simulation program. Creating of start-up path when load compensation is disabled (LC-) and voltage of source generator is constant may cause that in some substations the permissible voltage is exceeded.

TABLE II. THE VOLTAGE LEVEL OF NODES IN SUCCESIVE STAGES DURING THE CREATION OF START-UP PATH.

\begin{tabular}{|c|c|c|c|c|c|c|c|c|}
\hline \multirow{3}{*}{ 호 } & \multicolumn{8}{|c|}{ Nodes (see Fig. 7) } \\
\hline & 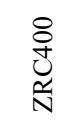 & 灾 & 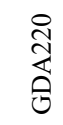 & 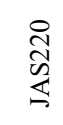 & 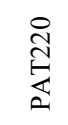 & 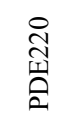 & 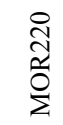 & 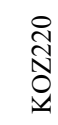 \\
\hline & $\mathrm{kV}$ & $\mathrm{kV}$ & $\mathrm{kV}$ & $\mathrm{kV}$ & $\mathrm{kV}$ & $\mathrm{kV}$ & $\mathrm{kV}$ & $\mathrm{kV}$ \\
\hline 1 & 380 & - & - & - & - & - & - & - \\
\hline 2 & 380 & 381 & - & - & - & - & - & - \\
\hline 3 & 380 & 381 & 205 & - & - & - & - & - \\
\hline 4 & 380 & 382 & 207 & 211 & - & - & - & - \\
\hline 5 & 380 & 383 & 208 & 217 & 218 & - & - & - \\
\hline 6 & 380 & 383 & 210 & 224 & 228 & 232 & - & - \\
\hline 7 & 380 & 382 & 207 & 213 & 211 & 208 & - & - \\
\hline 8 & 380 & 383 & 209 & 219 & 220 & 221 & 222 & - \\
\hline 9 & 380 & 383 & 211 & 225 & 231 & 234 & 239 & 240 \\
\hline
\end{tabular}

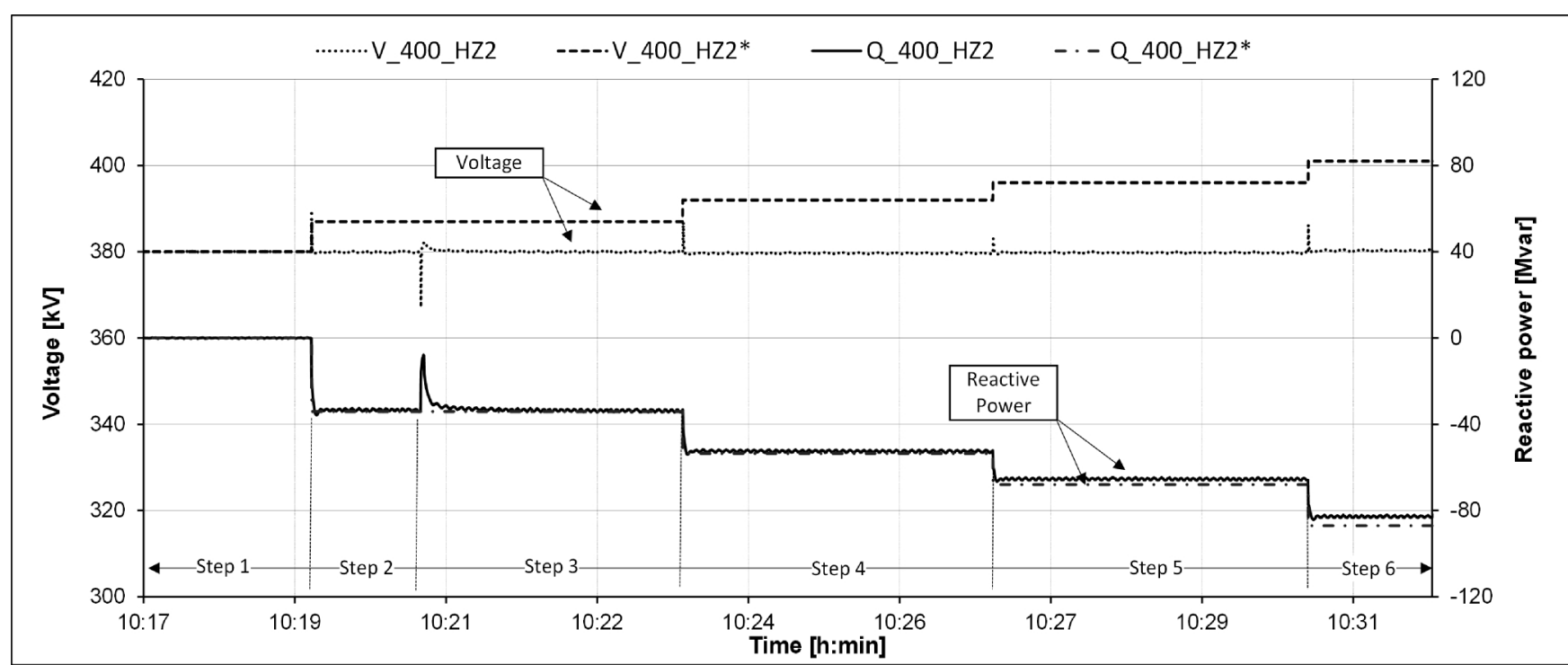

Fig. 8. Voltage and reactive power variation at Zarnowiec node (ZRC) during creation of start-up path (from step 1 to step 6 ) between Zarnowiec PSP and Kozienice TPP. Mark “*” describes voltage $V$ and reactive power $Q$ levels when load compensation is disabled (classic assumption - results of simulation). 
For $220 \mathrm{kV}$ lines in the Polish Power System the maximum permissible value is $245 \mathrm{kV}$ but at node $\mathrm{KOZ}$ (Fig. 9) voltage is equal to $254 \mathrm{kV}$ - it is not acceptable.

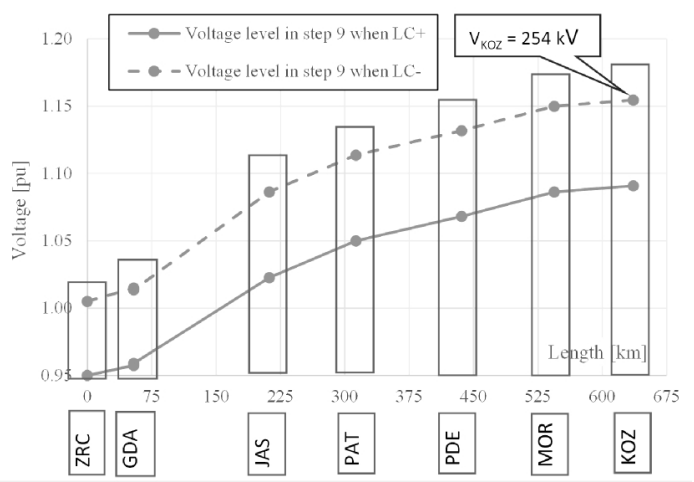

Fig. 9. Voltage values at the analysed nodes after creation of start-up path, step 9; (solid line - result of experiment when LC+, dashed line - result of simulation when LC-).

When load compensation in Zarnowiec PSP is enabled (LC+ $\Rightarrow Z_{\mathrm{LC}}=Z_{\mathrm{T}}$ ) - according to the authors proposition voltage at node $\mathrm{KOZ}$ is equal to $240 \mathrm{kV}$ (obtained during the experiment) and does not exceed permissible level $(245 \mathrm{kV})$.

\section{CONCLUSIONS}

The above presented results of the study show that it becomes necessary to verify the procedures for the preparation of start-up path. In order to reduce unfavourable increase of voltage level in prepared start-up path, the authors propose to enable load compensation (LC) impedance of load compensation should be $Z_{\mathrm{LC}}=Z_{\mathrm{LC}}$.

The power system experiment, which was carried out in May, 2015 for relatively long start-up path, proved that the modification proposed by the authors is advisable. Values of voltage in the nodes located on the start-up path are within the permissible range.

At present, voltage regulation during the creation of startup path is performed manually in Poland. Power system operator performs correction of the reference voltage at the generator terminals in order to achieve proper value of voltage in the power station high voltage terminals. It usually lasts a few minutes and it is very slow in terms of safety reasons. In the solution proposed by the authors the voltage correction is performed within 1 second.

\section{REFERENCES}

[1] K. Sroka, J. Lorenc, I. Grządzielski, Adaptation of large-scale generation units to defence and restoration of the Polish Power System, Safety of the Polish Power System, Scientific Publishers OWN, Poznan, 2009.

[2] I. Grzadzielski, K. Marszalkiewicz, K. Sroka, J. Borodynko, Check test and system trials as a base for detailed instructions on bringing voltage and start-up power from self-starting power plants, Safety of the Polish Power System Edition 2012, Scientific Publishers OWN, Poznan, 2012.

[3] M. Karwowski, M. Komarzyniec, A. Kurzynski, The experiment of activating Bydgoszcz II Combined Heat and Power-Plant from Koronowo Hydro Power Plant, Safety of the Polish Power System Edition 2012, Scientific Publishers OWN, Poznan, 2012.

[4] G. Pasiut, R. Kielak, R. Kuczynski, Defence and restoration test in Polish national grid during period 2009-2011, Safety of the Polish Power System Edition 2014, Scientific Publishers OWN, Poznan, 2014.

[5] I. Grzadzielski, K. Marszalkiewicz, K. Sroka, Operation of starting path from Dychow Hydro Power Plant to Dolna Odra Thermal Power Plant - simulation study, Safety of the Polish Power System Edition 2014, Scientific Publishers OWN, Poznan, 2014.

[6] H. Dytry, M. Niedzwiednik, W. Szweicer, S. Wroblewska, Z. Lubosny, "Hydrogenerator as a black-starter for a power plant. Protection requirements", CIGRE Conf., Paris, 2010.

[7] S. Corsi, M. Pozzi, "Voltage stability control for long lines black start-up", IEEE Power and Energy Society General Meeting Conversion and Delivery of Electrical Energy in the 21st Century, 2008, [Online]. Available: http://dx.doi.org/10.1109/PES.2008. 4596705.

[8] K. Madajewski, B. Sobczak, Selected Problems of voltage stability of Polish Power System, Safety of the Polish Power System, Scientific Publishers OWN, Poznan, 2009.

[9] B. Sobczak, R. Rink, M. Glaz, "Application of load compensation in voltage controllers of large generators in the Polish", ActaEnergetica, vol. 18, no. 1, 2014, [Online]. Available: http://dx.doi.org/10.12736/ issn.2300-3022.2014112

[10] P. Pentayya, A. Gartia, A. P. Das, C. Kumar, "Black start exercises experience in Western Region - India", IEEE India Conf. (INDICON), 2013. [Online]. Available: http://dx.doi.org/ 10.1109/INDCON.2013.6726046

[11] C. Wang, X. Niu, F. Li, et. al., "Consideration of pumped storage as a black-start source in Shandong power grid of China", IEEE Innovative Smart Grid Technologies - Asia (ISGT), 2012. [Online]. Available: http://dx.doi.org/10.1109/ISGT-Asia.2012.6303091

[12] H. Fendin, T. Hansen, M. Hemmingsson, D. Karlsson, "Black start test of the Swedish power system", IEEE Conf. PowerTech, Trondheim, 2011. [Online]. Available: http://dx.doi.org/10.1109/ PTC.2011.6019193

[13] M. M. Adibi, "Remote blackstart of steam electric station", IEEE Power Engineering Society Summer Meeting, 2002, [Online]. Available: http://dx.doi.org/10.1109/PESS.2002.1043523

[14] J. Ritonja, "Self-tuning control for synchronous machine stabilization", Elektronika ir Elektrotechnika, vol. 21, no. 4, 2015, pp. 7-12, [Online]. Available: http://dx.doi.org/10.5755/j01.eee. 21.4.12773

[15] R. Malkowski, S. Czapp, R. Kowalak, M. Losinski, "Study of the operation of synchronous generator voltage regulator during the creation of post blackout start-up path", Int. Conf. Information and Digital Technologies 2015, Zilina, Slovakia, 2015, pp. 239-243, [Online]. Available: http://dx.doi.org/10.1109/DT.2015.7222977

[16] IEEE Recommended Practice for Excitation System Models for Power System Stability Studies, IEEE Std 421.5 ${ }^{\mathrm{TM}}-2005$. 